\title{
Determination of the cultivar and aging of Sicilian olive oils using HPLC-MS and linear discriminant analysis ${ }^{\dagger}$
}

\author{
Pasquale Agozzino, ${ }^{a}$ Giuseppe Avellone, ${ }^{a}$ David Bongiorno, ${ }^{a, b *}$ \\ Leopoldo Ceraulo, ${ }^{a, b}$ Serena Indelicato, ${ }^{a, b}$ Sergio Indelicato ${ }^{a}$ \\ and Kàroly Vèkeyc
}

\begin{abstract}
A large number of certified samples (84) of Sicilian olive oils arising from the eight cultivars most represented in Sicily (Biancolilla, Cerasuola, Moresca, Nocellara del Belice, Nocellara Etnea, Oglialora Messinese, Brandofino and Tonda Iblea) have been collected and analyzed by HPLC/MS using an atmospheric pressure chemical ionization (APCI) source. The sample preparation is very simple; in fact, the oil samples are diluted without any chemical derivatization. A following statistical data treatment by general discriminant analysis (GDA) allows the determination of the olive oil cultivar. Furthermore, changes in the composition of glyceridic components of the olive oils lead to easy discrimination between fresh oils and 1-year-old samples. Copyright (C) 2010 John Wiley \& Sons, Ltd.
\end{abstract}

Keywords: olive oil; HPLC/MS; LDA; cultivar; aging

\section{Introduction}

Olive oil is one of the most important Italian food products and it is the most largely used edible oil in all the Mediterranean area. ${ }^{[1]}$ Due to its intrinsic nutritional values, several regulations and trademarks have been stated by the International Olive Oil Council and by the European Commission. ${ }^{[2]}$ Among all the existing olive oils, obtained from the grinding of olives, the extra virgin oil must be obtained simply by crushing and centrifugation procedures conducted at low temperature without any chemical treatment. Besides, extra virgin olive oils have to comply with a maximum acidic content (up to $0.8 \%$ free fatty acids, calculated as oleic acid) and are submitted to a panel test to evaluate the peculiar flavorings and tastes of the finest products.

These oils are complex mixtures containing a wide variety of substances and their composition is linked to cultivar, region, altitude, time of harvest and extraction process. The main fat components, that represent more than $98 \%$ of the total substances, are the triglycerides (TAGs) (consisting of three fatty acids linked to a glycerol backbone). The minor components are free fatty acids, vitamins, polyphenols, phytosterols, chlorophyll, carotenoids, mono and diacylglycerides.

In order to protect the names of regional foods and to ensure that only genuinely originating in specific regions products are marketed as such, the European Union instituted two geographical indications, protected designation of origin (PDO) and protected geographical indication (PGI). Italian olive oils are defined as PDO (Council Regulation, CEE-N.2082/92).

In spite of these criteria, at the moment, Italian extra virgin olive oil has become so lucrative that its adulteration constitutes the biggest source of agricultural fraud problems in the European Union. ${ }^{[1]}$
In the last few years, many studies have been performed to characterize and quantify each class of substances in olive oils and several different approaches have been developed to fight the frauds. They include both panel tests and analytical techniques. These latter can be used to analyze either the minor components ${ }^{[3-9]}$ or the principal components of olive oils or the whole oil. ${ }^{[10,11]}$

Our attention has been directed to the principal components fraction, theTAGs. These compounds can be determined according to different analytical approaches ${ }^{[12]}$ based on gas chromatography (such as GC/FID and GC/MS) after derivatization, ${ }^{\text {[13-15] }}$ high-performance liquid chromatography/mass spectrometry (HPLC/MS), ${ }^{[16]}$ matrix-assisted laser desorption-ionization/mass spectrometry (MALDI/MS) ${ }^{[17]}$ and nuclear magnetic resonance (NMR). ${ }^{[18,19]}$

Further, a statistical elaboration of raw data provides more detailed information on the characteristics of the oil samples not otherwise achievable. Currently, in literature, there are a number of studies in which principal component analysis $(P C A)^{[20,21]}$ or

\footnotetext{
* Correspondence to: David Bongiorno, Dipartimento di Chimica e Tecnologie Farmaceutiche, Università degli Studi di Palermo, Via Archirafi 32, 1-90123, Palermo, Italy.E-mail:dbongiorno@unipa.it

† This work was presented at the 1st Mass Spectrometry Food Day 2009, Dec 2nd and 3rd 2009, Parma, Italy

a Dipartimento di Chimica e Tecnologie Farmaceutiche, Università degli Studi di Palermo, Via Archirafi 32, I-90123, Palermo, Italy

b CGA-UNINETLAB, Università degli Studi di Palermo, Via F. Marini 14, I-90128, Palermo, Italy

c Chemical Research Center of the Hungarian Academy of Sciences, H-1025 Pusztaszeri út. 59, Budapest, Hungary
} 
cluster analysis $(C A)^{[22]}$ or linear discriminant analysis (LDA) ${ }^{[20,21,23]}$ are carried out.

On the basis of triacylglyceridic content, several methods have been developed in order to distinguish between different vegetable edible oils, ${ }^{[24,25]}$ or different grade olive oils (from extra virgin to lower quality oils).

In this work, numerous origin-certified samples of Sicilian olive oils have been analyzed using a HPLC/MS method and GDA, avoiding laborious sample preparations.

In fact, the main goal is to characterize and discriminate oils arising from the most widespread olive cultivars in the Sicilian territory, for both commercial and control purposes.

Moreover, since agronomic and technological factors may affect the oil's quality, ${ }^{[5,7,18]}$ the influences of the harvesting period and the altimetric zone of cultivation have been considered as well.

Finally, as the freshness of olive oils is strictly connected with their peculiar organoleptic and nutritional properties, it seemed of interest to study the aging effects on these products.

\section{Experimental}

\section{Chemicals}

Solvents used (methanol, n-hexane and water) were LC-MS grade from Sigma-Aldrich (Germany). Acetic acid (glacial) was purchased from Riedel-de Haen (Germany).

\section{Samples}

Eighty four Sicilian olive oil samples from eight different olive cultivars (Biancolilla, Cerasuola, Moresca, Nocellara del Belice, Nocellara Etnea, Oglialora Messinese, Brandofino and Tonda Iblea) were provided by producers involved in a quality research project of the Sicilian Government. Each sample was accompanied by a detailed form reporting precise geographical origin, harvesting period, altimetric zone and cultivar. The cultivars collected represent $80 \%$ of the total biodiversity of olive trees in Sicily. ${ }^{[26]}$

The olives were harvested in the crop year 2007, and according to the harvesting dates have been grouped in three periods: (1) the first half of November, (2) the second half of November and (3) December. The samples were also pooled, on the basis of the altimetric zones of cultivation, in three further groups: (1) 0-150 m above sea level (m.s.l.), (2) 150-300 m.s.l. and (3) above 300 m.s.l.

Following the collection of the olive oil samples, they were stored in cold room in the absence of light and analyzed within 3 months. These samples are considered as fresh oils. In order to simulate the homemade preservation of the oils, the same samples were stored in sealed brown bottles (in dark conditions and at room temperature) for 1 year and analyzed again as aged oils.

The sample preparation protocol applied is very simple and fast. It consists of a 3000 -fold dilution $(0.5 \mu \mathrm{l}$ of oil were diluted in methanol with $0.2 \%$ of acetic acid), and no derivatisation or time-consuming preliminary treatment of samples is required. ${ }^{[21]}$

\section{HPLC/MS analysis}

In order to separate and identify the triacylglycerols (TAGs), a ballistic HPLC method $^{[21]}$ has been developed. An Alliance 2695 (Waters) HPLC system equipped with autosampler, degasser and column heater coupled with a quadrupole time of flight (Waters Q-Tof Premier) mass spectrometer, has been used.
The compounds were separated by a Thermo beta Basic C18 column $(5 \mathrm{~cm} \times 2.1 \mathrm{~mm}$ i.d., particle size $1.8 \mu \mathrm{m})$ under the following conditions: column temperature, $20^{\circ} \mathrm{C}$; injected volume, $10 \mu \mathrm{l}$.

All samples have been injected in duplicate using a thermostated autosampler, maintained at $4{ }^{\circ} \mathrm{C}$. The HPLC analyses were carried out using a stepwise gradient program combining solvent $A$ (methanol/water, $90 / 10, v / v \%$ ), containing $0.2 \%$ acetic acid, and solvent B (methanol/n-hexane, 90/10 v/v\%),containing $0.2 \%$ acetic acid. The elution gradient for HPLC separation changed according to the following conditions: from 0 to $1 \mathrm{~min}, 100 \% \mathrm{~A}$ (flow rate $0.2 \mathrm{ml} / \mathrm{min}$ ), from 1.01 to $10 \mathrm{~min}, 100 \% \mathrm{~B}$ (flow rate $0.2 \mathrm{ml} / \mathrm{min}$ ), from 12 to $20 \mathrm{~min}$ the same percentage of solvent B was maintained at flow $0.7 \mathrm{ml} / \mathrm{min}$, from 20 to $21 \mathrm{~min} 100 \% \mathrm{~B}$ (flow rate $0.2 \mathrm{ml} / \mathrm{min}$ ) and then from 21.01 to $31 \mathrm{~min}, 100 \% \mathrm{~A}$ (flow rate $0.2 \mathrm{ml} / \mathrm{min}$ ). The MS experiments were performed on Q-Tof Premier using dynamic range enhancement (DRE) as acquisition mode that avoids MCP saturation keeping a fairly good sensitivity. This allows to correctly quantify very abundant as well as tracelevel compounds, providing results more suitable for a statistical analysis.

Atmospheric pressure chemical ionisation (APCI) has been used in positive mode under the following conditions: corona probe current, $4 \mu \mathrm{A}$; corona voltage, $3.6 \mathrm{KV}$; probe temperature, $450.0^{\circ} \mathrm{C}$; sampling cone, $19.0 \mathrm{~V}$; extraction cone, $4.3 \mathrm{~V}$; ion guide, $1.2 \mathrm{~V}$; source temperature $90^{\circ} \mathrm{C}$, cone gas, $\mathrm{N}_{2}$, flow $50.0 \mathrm{l} / \mathrm{h}$; desolvation gas, $\mathrm{N}_{2}$, flow $600.0 \mathrm{l} / \mathrm{h}$.

\section{Statistical analysis}

The collected data were submitted to a statistical analysis using the Statsoft Statistica 7 software package. The dataset obtained from chromatogram integration was refined, taking into account only the peaks common to all the samples.

The numerical descriptors that are finally included in the data matrix have been obtained through the following procedure: the peak height of each compound previously considered is divided by the sum of the peak heights of all the considered compounds. This generates a number that is expression of a chromatographic purity. This refined data matrix has been used for the following statistical analysis.

Given the quite large number of starting variables, a GDA approach has been used to investigate the dataset. GDA is a multivariate $\operatorname{LDA}^{[27,28]}$ method belonging to the so-called supervised statistical regressions. This statistical approach, given a number of independent variables (in this case the chromatographic purity expression of each component), determines the maximum variance between groups expressed by $n$ categorical descriptors (dependent variables). The statistical regression generates $n-1$ canonical roots, containing the sample coordinates (canonical scores) in an $n-1$ dimensional space.

In order to discriminate oils on the basis of some categorical descriptors such as cultivars, altimetric zone, harvesting period and oil aging, a forward stepwise method has been applied.

\section{Results and Discussion}

A good separation of major components in the 10-12.5 min retention time window has been achieved through our HPLC method (Fig. 1). Nevertheless, the chromatograms obtained from the different cultivars are very close to each other, so a 

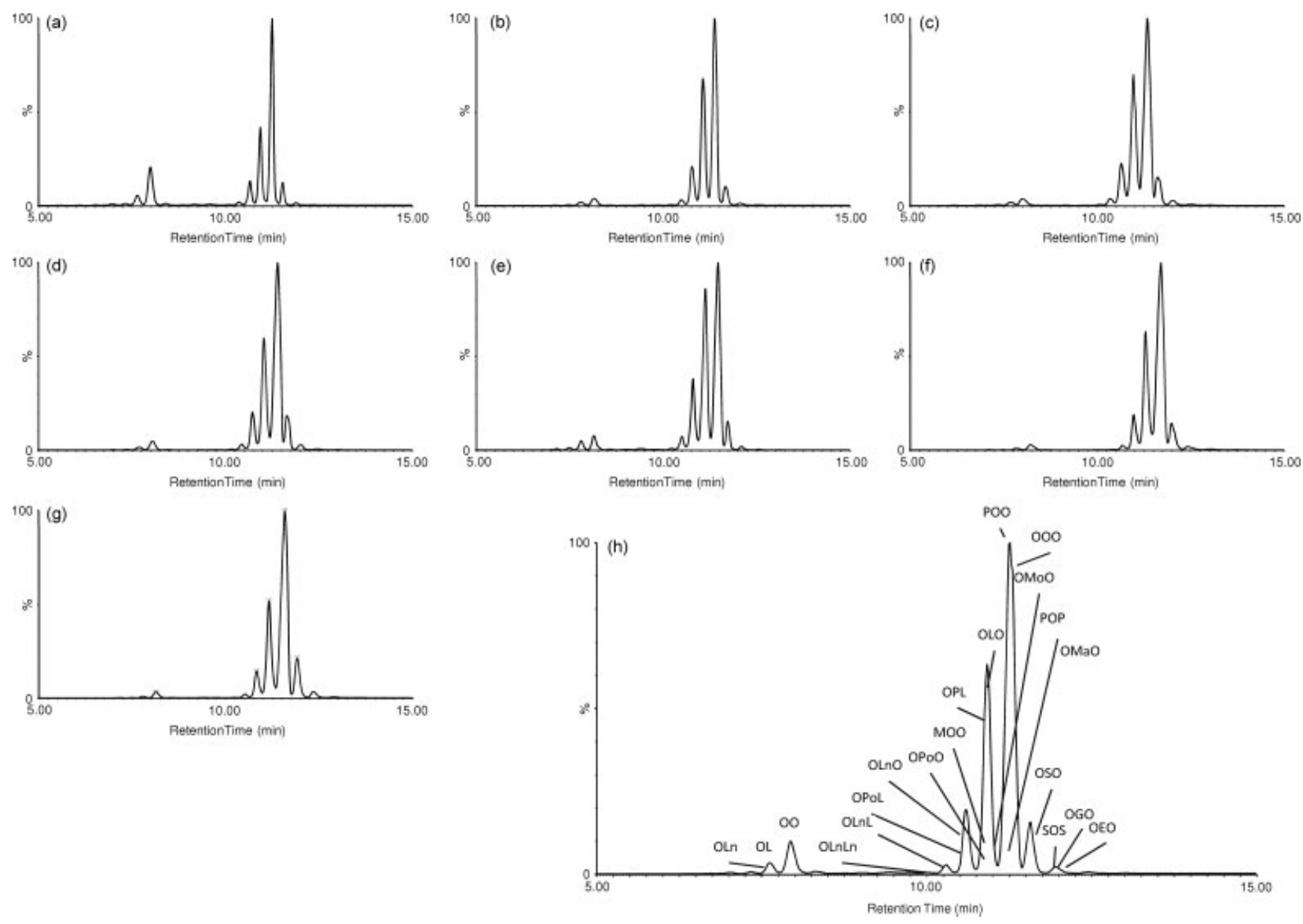

Figure 1. (a-h) Typical chromatograms of main olive oil cultivars: (a) Ogliarola Messinese; (b) Nocellara Etnea; (c) Tonda Iblea; (d) Biancolilla; (e) Moresca; (f) Brandofino; (g) Nocellara del Belice; (h) Cerasuola. Fatty acids abbreviations: Myristic (M), Palmitoleic (Po), Palmitic (P), Heptadecanoic (Mo), Margaric (Ma), Linolenic (Ln), Linoleic (L), Oleic (O), Stearic (S), Gadoleic (G), Arachidic (A), Behenic (B), Lignoceric (Li), Eicosanoic (E).

discrimination of cultivars according to the simple TIC (total ion chromatogram) traces must be excluded.

Each TIC shows only 12 relevant peaks due to major components (Fig. 1). However a deeper inspection, achieved by observing all the mass spectra collected during the chromatographic process, shows the presence of at least 230 independent substances. It is not possible to evidence, within the TIC traces, several minor components that are easily found through a more careful analysis of the chromatograms. Thus, a scan-by-scan inspection of the corresponding mass spectra was made in order to find a reproducible trend of ions belonging to an individual specie. This inspection was performed on four different chromatograms belonging to four different cultivars. The extracted ion chromatograms, obtained from the raw TIC data, were used to develop an automated processing method. This latter was applied to all the chromatograms collected to determine the components peak height.

The so-obtained data have been submitted to the statistical analysis using a GDA approach. In a previous work we also obtained good results ${ }^{[21]}$ from LDA technique, using a few number (7) of variables. However, while in that case only three cultivars were analyzed, in the current work their higher number, turned into further degrees of freedom, does not allow us to obtain a good discrimination with such a small number of variables.

In order to obtain a good classification, a subset of 50 varietally pure samples (purity $>90 \%$ ) was analyzed. The model was made through a stepwise procedure to reduce overfitting with a final number of ten variables. In particular, the selected variables are listed in Table 1. The 2D graph for cultivar classification is reported in Fig. 2.

Robustness of the obtained statistical models has been checked through external validation procedures. These check the accuracy of a predictive model when it is applied in practice.

In external validation procedures, data are partitioned into two complementary subsets, the training set and the testing one. The analysis is performed on the training set, and it is validated using the testing set. This is constituted by about $10 \%$ of samples, which are excluded during the statistical modeling procedure and, finally, during the test procedure, are analyzed as unknown. The correctness of their group assignment is usually checked automatically by the software.

In our case, the final results indicate that for fresh (less than 3 months of age) olive oils the discrimination on the basis of cultivar is possible. The statistical model is $100 \%$ able to correctly classify both model and external validation samples.

The same results are obtained through stepwise backward removal and stepwise forward modeling approaches. During the development of the method, the stepwise approach was preferred in order to reduce the variables to a reasonable number (until 10). This number still guarantees an effective sample discrimination and represents a reliable base for further investigations. Even if is not strictly necessary for a statistical analysis, several discriminant compounds have been identified on the basis of molecular weight and retention time, according to literature. ${ }^{[16,21]}$ The discrimination 
Table 1. List of variables to separate extra virgin olive oils

\begin{tabular}{|c|c|c|c|c|c|c|c|c|c|c|c|}
\hline \multirow[b]{2}{*}{ Model } & \multicolumn{3}{|c|}{$\begin{array}{l}\text { Discriminating } \\
\text { variables }\end{array}$} & \multirow[b]{2}{*}{ Model } & \multicolumn{3}{|c|}{$\begin{array}{c}\text { Discriminating } \\
\text { variables }\end{array}$} & \multirow[b]{2}{*}{ Model } & \multicolumn{3}{|c|}{$\begin{array}{l}\text { Discriminating } \\
\text { variables }\end{array}$} \\
\hline & $m / z\left(\mathrm{MH}^{+}\right)$ & RT & AG & & $m / z\left(\mathrm{MH}^{+}\right)$ & RT & AG & & $m / z\left(\mathrm{MH}^{+}\right)$ & RT & AG \\
\hline \multirow[t]{14}{*}{$\begin{array}{l}\text { Fresh oils, by } \\
\text { cultivar }\end{array}$} & & & & $\begin{array}{l}\text { Aged oils, by } \\
\text { cultivar }\end{array}$ & & & & $\begin{array}{l}\text { Fresh and aged } \\
\text { oils, by aging }\end{array}$ & & & \\
\hline & 575 & 10.9 & OPo & & 603 & 8.1 & $\mathrm{OO}$ & & 603 & 8.1 & $\mathrm{OO}$ \\
\hline & 617 & 7.5 & $\mathrm{AO}$ & & 617 & 7.5 & OLn & & 805 & 11.3 & POM \\
\hline & 621 & 8.1 & $\mathrm{OO}$ & & 617 & 7.5 & $\mathrm{AO}$ & & 885 & 11.3 & OLS \\
\hline & 801 & 10.2 & PoPoPo & & 801 & 10.2 & PoPoPo & & 889 & 11.7 & SOS \\
\hline & 869 & 10.8 & OLMo & & 829 & 10.5 & OLM & & 971 & 13.0 & LiOO \\
\hline & 873 & 11.4 & $\mathrm{OMaO}$ & & 831 & 10.9 & PLP & & & & \\
\hline & 877 & 10.1 & OLnLn & & 831 & 10.5 & OOM & & & & \\
\hline & 889 & 11.7 & SOS & & 851 & 10.0 & LnLnP & & & & \\
\hline & 913 & 11.6 & OGO & & 871 & 11.1 & $\mathrm{OMoO}$ & & & & \\
\hline & 913 & 11.6 & OLA & & 873 & 11.4 & $\mathrm{OMaO}$ & & & & \\
\hline & & & & & 913 & 11.6 & OGO & & & & \\
\hline & & & & & 915 & 11.6 & GOS & & & & \\
\hline & & & & & 943 & 12.5 & ОВО & & & & \\
\hline
\end{tabular}

RT: retention times, AG: acyl glycerols; Fatty acids abbreviations: Myristic (M), Palmitoleic (Po), Palmitic (P), Heptadecanoic (Mo), Margaric (Ma), Linolenic (Ln), Linoleic (L), Oleic (O), Stearic (S), Gadoleic (G), Arachidic (A), Behenic (B), Lignoceric (Li).

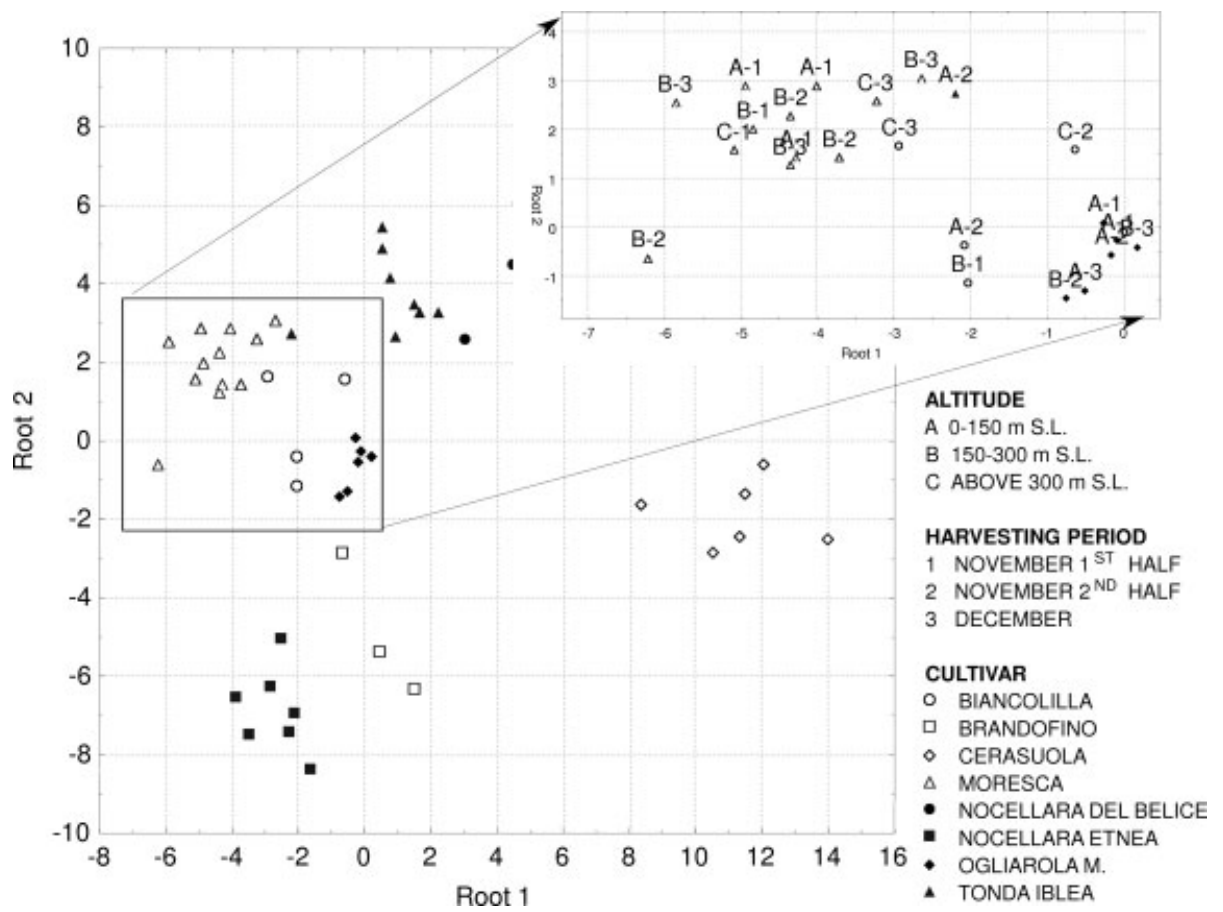

Figure 2. Separation of olive oil cultivars using GDA analysis of the HPLC/MS results. In the GDA analysis, 10 variables (peak intensities) were used to separate 50 extra virgin olive oil samples. External validation shows $98 \%$ probability for successful identification.

criteria obtained are satisfactory with a good variance between groups/variance within the group ratio $(F \gg 1)$ and very good significance levels $(p \ll 0.05)$ (Table 2$)$.

Discriminations were also attempted on studying the influence of harvesting period (the first half of November, the second half of November and December) and altimetric zone of cultivation (0-150 m.s.l.; 150-300 m.s.l. and above 300 m.s.l.). It has been established that these do not influence the results significantly.

As shown in the scatter plot (Fig. 2, inset), data points belonging to the same cultivar and with different harvesting time or altitude are close to each other, not showing any particular spatial distribution within each group due to these different characteristics.

This demonstrates that there is a partial compensation for the effects of harvesting period and altitude of plantations on the degree of ripening of the drupes. This implies a certain equalization of their chemical differences in TAG fractions due to these effects.

Another goal of this work was to study the same samples after 1 year of aging and to evaluate whether differences between the oils of different cultivars are still appreciable in spite of the 
Table 2. $F$ and $p$ values for the discrimination between the different cultivars analyzed using ten variables

\begin{tabular}{|c|c|c|c|c|c|c|c|c|}
\hline & OGLIAROLA M. & BIANCOLILLA & $\begin{array}{c}\text { NOCELLARA } \\
\text { ETNEA }\end{array}$ & BRANDOFINO & NOCELLARA DEL B. & CERASUOLA & MORESCA & $\begin{array}{l}\text { TONDA } \\
\text { IBLEA }\end{array}$ \\
\hline & $F$ values & & & & & & & \\
\hline OGLIAROLA M. & & 5.37090 & 15.05824 & 7.15830 & 11.72946 & 31.28952 & 15.66790 & 11.73816 \\
\hline BIANCOLILLA & 5.37090 & & 13.46241 & 6.55594 & 12.59535 & 32.08172 & 8.81772 & 6.10772 \\
\hline NOCELLARA ETNEA & 15.05824 & 13.46241 & & 4.17832 & 32.17727 & 45.10467 & 27.26901 & 32.05159 \\
\hline BRANDOFINO & 7.15830 & 6.55594 & 4.17832 & & 15.79968 & 19.79485 & 16.82989 & 13.04029 \\
\hline NOCELLARA DEL B. & 11.72946 & 12.59535 & 32.17727 & 15.79968 & & 15.96893 & 19.80186 & 5.34270 \\
\hline CERASUOLA & 31.28952 & 32.08172 & 45.10467 & 19.79485 & 15.96893 & & 63.21469 & 34.25231 \\
\hline MORESCA & 15.66790 & 8.81772 & 27.26901 & 16.82989 & 19.80186 & 63.21469 & & 16.16688 \\
\hline \multirow[t]{2}{*}{ TONDA IBLEA } & 11.73816 & 6.10772 & 32.05159 & 13.04029 & 5.34270 & 34.25231 & 16.16688 & \\
\hline & $p$ values & & & & & & & \\
\hline OGLIAROLA M. & & 0.000203 & 0.000000 & 0.000018 & 0.000000 & 0.000000 & 0.000000 & 0.000000 \\
\hline BIANCOLILLA & 0.000203 & & 0.000000 & 0.000038 & 0.000000 & 0.000000 & 0.000002 & 0.000070 \\
\hline NOCELLARA ETNEA & 0.000000 & 0.000000 & & 0.001326 & 0.000000 & 0.000000 & 0.000000 & 0.000000 \\
\hline BRANDOFINO & 0.000018 & 0.000038 & 0.001326 & & 0.000000 & 0.000000 & 0.000000 & 0.000000 \\
\hline NOCELLARA DEL B. & 0.000000 & 0.000000 & 0.000000 & 0.000000 & & 0.000000 & 0.000000 & 0.000212 \\
\hline CERASUOLA & 0.000000 & 0.000000 & 0.000000 & 0.000000 & 0.000000 & & 0.000000 & 0.000000 \\
\hline MORESCA & 0.000000 & 0.000002 & 0.000000 & 0.000000 & 0.000000 & 0.000000 & & 0.000000 \\
\hline TONDA IBLEA & 0.000000 & 0.000070 & 0.000000 & 0.000000 & 0.000212 & 0.000000 & 0.000000 & \\
\hline
\end{tabular}

changes in the composition of glyceridic components. Hence, we performed a statistical analysis on the HPLC-MS data trying to discriminate the oil samples according to the cultivars, regardless of their freshness. Analyzing 100 samples (50 fresh and 50 aged oils), we achieved a discrimination of $94 \%$ of cultivar with a $92 \%$ of correct external validation using 20 variables (graph not reported). In spite of these good results, in terms of percentage of correct assignation or external validation, the model was not able to discriminate properly between the oils belonging to the Biancolilla and the Ogliarola Messinese cultivars, showing a $p$ value of 0.9. This result confirms that the aging processes on the TAGs, mainly constituted by hydrolysis or oxidations, ${ }^{[29]}$ lead to a certain leveling out of the chemical differences among the samples and consequently of the peculiar characteristics of each cultivar. In addition to these drawbacks, the number of variables used for such a discrimination was quite high, and therefore the model was finally discarded.

The results lead us to build a specific model entirely based on 50 aged oils using 13 variables (Table 3 ).

This analysis was able to provide $98 \%$ of cultivar discrimination and $100 \%$ of external validation results.

The 2D separation is showed in Fig. 3.

Finally, a further statistical model has been developed to discriminate, independently from the cultivars, fresh and aged olive oils. Indeed, it is well known that several beneficial and organoleptic properties of olive oils are strictly related to the freshness of the product, as most of the antioxidants and flavors are subjected to oxidation and progressive depletion processes. ${ }^{[29]}$ Thus, aged olive oils and eventual mixtures of fresh/aged olive oils turn out to be generally less attractive and lower value products. To develop this model, we analyzed 100 oil samples (50 fresh oils and 50 aged ones) and reduced the number of variable to only 5 . The results of the model are showed in Fig. 4.

Both $F$ and $p$ values, achieved for discrimination between fresh and aged oils, are extremely good (Table 4).

This discrimination model provides a new parameter, directly linked to the aging of olive oils. In fact, up to date, only few

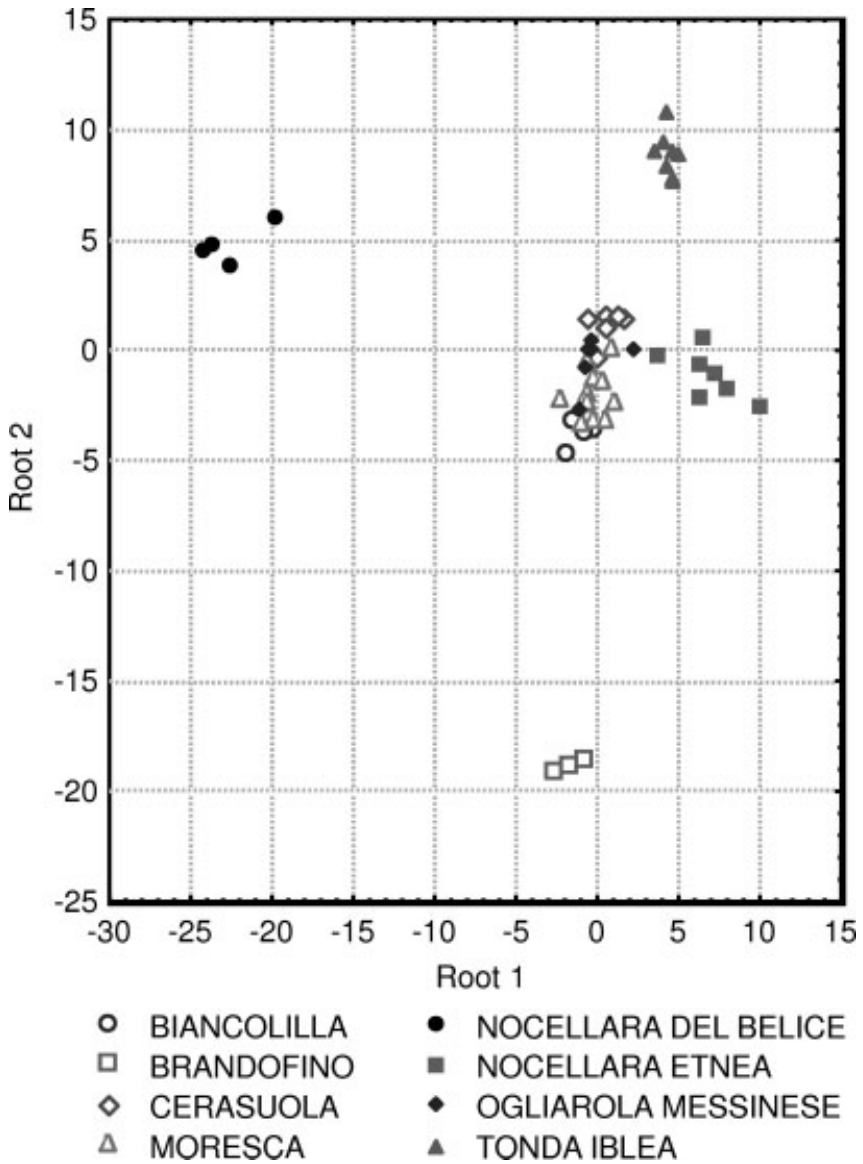

Figure 3. Separation of aged olive oil cultivars using GDA analysis of the HPLC/MS results. In the GDA analysis, 13 variables (peak intensities) were used to separate 50 extra virgin olive oil samples. External validation shows $100 \%$ probability for successful identification. 
Table 3. $F$ and $p$ values for the discrimination between the different cultivars of aged extra virgin oils analyzed using 13 variables

\begin{tabular}{|c|c|c|c|c|c|c|c|c|}
\hline & OGLIAROLA M. & BIANCOLILLA & $\begin{array}{c}\text { NOCELLARA } \\
\text { ETNEA }\end{array}$ & BRANDOFINO & NOCELLARA DEL B. & CERASUOLA & MORESCA & $\begin{array}{l}\text { TONDA } \\
\text { IBLEA }\end{array}$ \\
\hline & $F$ values & & & & & & & \\
\hline OGLIAROLA M. & & 1.63240 & 13.39390 & 35.37328 & 56.25726 & 7.87386 & 1.85648 & 22.95601 \\
\hline BIANCOLILLA & 1.63240 & & 12.39514 & 24.81233 & 44.99397 & 7.90179 & 2.57754 & 27.39657 \\
\hline NOCELLARA ETNEA & 13.39390 & 12.39514 & & 41.36734 & 99.11268 & 21.85063 & 21.99682 & 28.60323 \\
\hline BRANDOFINO & 35.37328 & 24.81233 & 41.36734 & & 66.57971 & 40.92785 & 37.67715 & 65.09831 \\
\hline NOCELLARA DEL B. & 56.25726 & 44.99397 & 99.11268 & 66.57971 & & 63.07396 & 73.09723 & 86.86638 \\
\hline CERASUOLA & 7.87386 & 7.90179 & 21.85063 & 40.92785 & 63.07396 & & 13.32414 & 22.30967 \\
\hline MORESCA & 1.85648 & 2.57754 & 21.99682 & 37.67715 & 73.09723 & 13.32414 & & 39.49656 \\
\hline \multirow[t]{2}{*}{ TONDA IBLEA } & 22.95601 & 27.39657 & 28.60323 & 65.09831 & 86.86638 & 22.30967 & 39.49656 & \\
\hline & $p$ values & & & & & & & \\
\hline OGLIAROLA M. & & 0.150372 & 0.000000 & 0.000000 & 0.000000 & 0.000015 & 0.097042 & 0.000000 \\
\hline BIANCOLILLA & 0.150372 & & 0.000000 & 0.000000 & 0.000000 & 0.000015 & 0.024313 & 0.000000 \\
\hline NOCELLARA ETNEA & 0.000000 & 0.000000 & & 0.000000 & 0.000000 & 0.000000 & 0.000000 & 0.000000 \\
\hline BRANDOFINO & 0.000000 & 0.000000 & 0.000000 & & 0.000000 & 0.000000 & 0.000000 & 0.000000 \\
\hline NOCELLARA DEL B. & 0.000000 & 0.000000 & 0.000000 & 0.000000 & & 0.000000 & 0.000000 & 0.000000 \\
\hline CERASUOLA & 0.000015 & 0.000015 & 0.000000 & 0.000000 & 0.000000 & & 0.000000 & 0.000000 \\
\hline MORESCA & 0.097042 & 0.024313 & 0.000000 & 0.000000 & 0.000000 & 0.000000 & & 0.000000 \\
\hline TONDA IBLEA & 0.000000 & 0.000000 & 0.000000 & 0.000000 & 0.000000 & 0.000000 & 0.000000 & \\
\hline
\end{tabular}

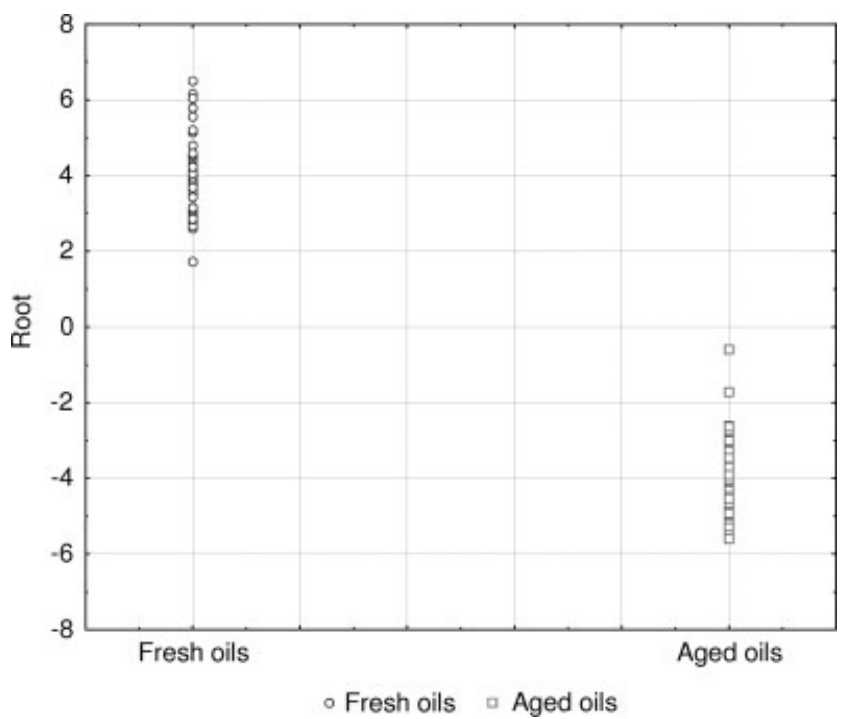

Figure 4. Separation of aged and fresh olive oils using GDA analysis of the HPLC/MS results. In the GDA analysis, 5 variables (peak intensities) were used to separate 100 extra virgin olive oil samples. External validation shows $100 \%$ probability for successful identification.

methods are reported for the estimate of the freshness of olive oils and to discriminate their different storage conditions. They consist on the determination of the ratio 1,2-/1,3- diacylglycerides (DG) by GC analysis after silylation ${ }^{[30]}$ or the determination of E-2-Hexenal, $\mathrm{K}_{232}$ and $\mathrm{K}_{270}$ as markers of virgin olive oil freshness. ${ }^{[31]}$

\section{Conclusions}

The product quality certification is particularly important to identify regional specialties and high quality products, such as extra virgin olive oils. It is indispensable to protect high quality products in the face of competition from low cost, poor

\begin{tabular}{|c|c|c|}
\hline & Fresh oil & Aged oil \\
\hline & $F$ value & \\
\hline Fresh oil & & 254.7779 \\
\hline \multirow[t]{2}{*}{ Aged oil } & 254.7779 & \\
\hline & $p$ value & \\
\hline Fresh oil & & 0.00 \\
\hline Aged oil & 0.00 & \\
\hline
\end{tabular}

quality substitutes. Quality control requires that frauds should be possibly identified using objective, analytical measurements. In Sicily, there is a strict correspondence between the cultivars and the geographical zones in which they are cultivated. Therefore, identification of the cultivar from the Sicilian olive-derived products (such as extra virgin olive oils) may suggest also an indication of geographical provenance.

The analytical method developed is based on HPLC-MS. It is easy to use in industrial environment and does not require derivatization or cleanup procedures. The time required for each analysis is quite short and could easily be shortened even more if needed. The developed statistical model (GDA) makes it easy to distinguish olive oils produced from various cultivars. A validation procedure shows that it is not only selective but also robust.

The same analytical technique can be used for a variety of other purposes as well. It is feasible to use it to identify degradation due to aging (the results clearly show a large difference between fresh product and 1-year-old extra virgin olive oil), as well as to confirm that the aging processes lead to a certain leveling out of the peculiar differences among the cultivar. It would also be feasible to use the developed method to check if fresh and old olive oils are mixed. The results obtained also show that altitude and harvesting period tend to compensate each other demonstrating that an anticipation or delay of the harvesting period can be 
effectively used to guarantee a high quality of the product. The described methodology seems adequate to check various other characteristics or features of olive oils, and is likely to be useful to identify other specialty oils.

\section{Acknowledgements}

This work has been encouraged by the Sicilian Regional Government.

The financial support of the University of Palermo Fondi Ricerca Scientifica ex $60 \%$ is gratefully acknowledged.

\section{References}

[1] I.O.O. Council, Olive 92, 2002, 22.

[2] EU, Off. J. Commission Eur. Commun., Regulation No. 2632/94 L208, 1996.

[3] R. Bucci, A. D. Magri, A. L. Magri, D. Marini, F. Marini. Chemical authentication of extra virgin olive oil varieties by supervised chemometric procedures. J. Agric. Food Chem. 2002, 50, 413.

[4] F. Marini. F. Balestrieri, R. Bucci, A. D. Magri, A. L. Magri, D. Marini, F. Marini, Supervised pattern recognition to authenticate Italian extra virgin olive oil varieties. Chemometr. Intell. Lab. Syst. 2004, 73, 85.

[5] M. D. Salvador, F. Aranda, S. Gómez-Alonso, G. Fregapane. Influence of extraction system, production year and area on Cornicabra virgin olive oil: a study of five crop seasons. Food Chem. 2003, 80, 359.

[6] D. Krichene, W. Taamalli, D. Daoud, M. D. Salvador, G. Fregapane, M. Zarrouk. Phenolic compounds, tocopherols and other minor components in virgin olive oils of some Tunisian varieties. J. Food Biochem. 2007, 31, 179.

[7] M. M. Torres, D. M. Maestri. The effects of genotype and extraction methods on chemical composition of virgin olive oils from Traslasierra Valley, Córdoba, Argentina. Food Chem. 2006, 96, 507.

[8] A. Cichelli, G. P. Pertesana. High-performance liquid chromatographic analysis of chlorophylls, pheophytins and carotenoids in virgin olive oils: chemometric approach to variety classification. J. Chromatogr. A 2004, 1046, 141.

[9] G. Luna, M. T. Morales, R. Aparicio. Characterisation of 39 varietal virgin olive oils by their volatile compositions. Food Chem. 2006, 98, 243

[10] F. Camin, R. Larcher, M. Perini, L. Bontempo, D. Bertoldi, G. Gagliano, G. Nicolini, G. Versini. Characterisation of authentic Italian extravirgin olive oils by stable isotope ratios of $\mathrm{C}, \mathrm{O}$ and $\mathrm{H}$ and mineral composition. Food Chem. 2010, 118, 901.

[11] M. J.Lerma-García, J. M. Herrero-Martínez, G. Ramis-Ramos, E. F. Simó-Alfonso. Prediction of the genetic variety of Spanish extra virgin olive oils using fatty acid and phenolic compound profiles established by direct infusion mass spectrometry. Food Chem. 2008, 108, 1142.

[12] A. Ranalli, L. Pollastri, S. Contento, G. Di Loreto, E. lannucci, L. Lucera, F. Russi. Acylglycerol and fatty acid components of pulp, seed, and whole olive fruit oils. Their use to characterize fruit variety by chemometrics. J. Agric. Food Chem. 2002, 50(13), 3775.

[13] G. Di Bella, R. Maisano, L. La Pera, V. Lo Turco, F. Salvo, G. Dugo. Statistical characterization of sicilian olive oils from the Peloritana and Maghrebian zones according to the fatty acid profile. J. Agric. Food Chem. 2007, 55(16), 6568. DOI: 10.1021/jf070523r.

[14] N.Doubois, C. Barthomeuf, J.P. Bergé. Gas chromatographic behavior of fatty acid derivatives for mass spectrometry on lowpolarity capillary columns. Eur. J. Lipid Sci. Technol. 2009, 111(7), 688.
[15] G. Dobson, W. W. Christie. Spectroscopy and spectrometry of lipids (Part 2) - mass spectrometry of fatty acid derivatives. Eur. J. Lipid Sci. Technol. 2002, 104, 36

[16] M. Holcapek, P. Jandera, P. Zderadicka, L. Hrub. Characterization of triacylglycerol and diacylglycerol composition of plant oils using high-performance liquid chromatography-atmospheric pressure chemical ionization mass spectrometry. J. Chromatogr. A 2003, 1010, 195.

[17] G. R. Asbury, K. Al-Saad, W. F. Siems, R. M. Hannan, H. H. Hill Jr. Analysis of triacylglycerols and whole oils by matrix-assisted laser desorption/ionization time of flight mass spectrometry. J. Am. Soc. Mass Spectrom. 1999, 10(10), 983.

[18] M. D'Imperio, L. Mannina, D. Capitani, O. Bidet, E. Rossi, F. M. Bucarelli, G. B. Quaglia, A. Segre. NMR and statistical study of olive oils from Lazio: a geographical, ecological and agronomic characterization. Food Chem. 2007, 105, 1256.

[19] P. Fronimaki, A. Spyros, S. Christophoridou, P. Dais. Determination of the diglycerides content in Greek virgin olive oils and some commercial olive oils by employing 31P NMR spectroscopy. J. Agric. Food Chem. 2002, 50, 2207.

[20] S. Lanteri, C. Armannino, E. Perri, A. Palopoli. Study of oils from Calabrian olive cultivars by chemometric method. Food Chem. 2002, 76, 501

[21] K. Nagy, D. Bongiorno, G. Avellone, P. Agozzino, L. Ceraulo, K. Vèkey. High performance liquid chromatography-mass spectrometry based chemometric characterization of olive oils. J. Chromatogr. A 2005, 1078, 90.

[22] F. Guimet, R. Boqué, J. Ferré. Cluster analysis applied to the exploratory analysis of commercial Spanish olive oils by means of excitation-emission fluorescence spectroscopy. J. Agric. Food Chem. 2004, 52(22), 6673, DOI:10.1021/jf040169m.

[23] A. Agiomyrgianaki, P. V. Petrakis, P. Dais. Detection of refined olive oil adulteration with refined hazelnut oil by employing NMR spectroscopy and multivariate statistical analysis. Talanta 2009, DOI:10.1016/j.talanta.2009.11.024 (available online 12 November 2009).

[24] J. Parcerisa, I. Casals, J. Boatella, R. Codony, M. Rafecas. Analysis of olive and hazelnut oil mixtures by high-performance liquid chromatography-atmospheric pressure chemical ionisation mass spectrometry of triacylglycerols and gas-liquid chromatography of non-saponifiable compounds (tocopherols and sterols). J. Chromatogr. A 2000, 88, 149.

[25] N. K. Andrikopoulos, I. G. Giannakis, V. Tzamtzis. Analysis of olive oil and seed oil triglycerides by capillary gas chromatography as a tool for the detection of the adulteration of olive oil. J. Chromatogr. Sci. 2001, 39, 137

[26] T. Caruso, D. Cartabellotta, A. Motisi. Cultivar di Olivo Siciliane. Identificazione, validazione, caratterizzazione morfologica e molecolare e qualità degli oli, 1st ed, Regione Siciliana, Assessorato Agricoltura e Foreste: 2007.

[27] R. O. Duda, P. E. Hart. Pattern Classification and Scene Analysis, John Wiley \& Sons: New York, 1973.

[28] R. I. Jennrich. In Stepwise Discriminant Analysis in Statistical Methods forDigital Computers, K. Enslein, A. Ralston and H. S. Wilf (Eds). Wiley: New York, 1977.

[29] E. Aprea, F. Biasioli, G. Sani, C. Cantini, T. D. Märk, F. Gasperi. Proton transfer reaction-mass spectrometry (PTR-MS) headspace analysis for rapid detection of oxidative alteration of olive oil. J. Agric. Food Chem. 2006, 54, 7635 .

[30] H.D. Belitz, W. Grosch, P. Schieberle, Food Chemistry, Springer Verlag: Berlin, 2009.

[31] C. M. Kalua, D. R. Bedgood, A. G. Bishop, PI.D. Prenzler. Discrimination of storage conditions and freshness in virgin olive oil. J. Agric. Food Chem. 2006, 54(19), 7144. 